\title{
In Vitro Autoantibody Production by Normal Adult and Cord Blood B Cells
}

\author{
David S. Pisetsky, Diane F. Jelinek, Laurie M. McAnally, Charles F. Reich, and Peter E. Lipsky \\ Medical Service, Durham Veterans Administration Hospital, and Division of Rheumatology and Immunology, Duke University \\ Medical Center, Durham, North Carolina 27705; and Rheumatic Diseases Division, Department of Internal Medicine,
}

University of Texas Health Science Center, Dallas, Texas 75235

\begin{abstract}
To investigate the repertoire of autoantibodies in humans, anti-DNA and rheumatoid factor (RF) production in vitro was assessed in cultures of adult peripheral blood $B$ cells and neonatal umbilical venous blood B cells. B cells were stimulated under various culture conditions, using an immobilized monoclonal anti-CD3 antibody and adult $\mathbf{T}$ cells or Staphylococcus aureus (SA) in the presence or absence of adult $T$ cells or factors derived from mitogen-stimulated adult $T$ cells as polyclonal B cell activators. Total IgM, as well as IgM anti-DNA and RF, were assessed by ELISA. Total IgM production was induced from adult and neonatal $B$ cells with $S A$ plus $T$ cell factors, as well as anti-CD3-stimulated $T$ cells. RF was induced from adult and cord blood $B$ cells by either mode of stimulation, whereas significant anti-DNA production was observed only when $B$ cells were stimulated with anti-CD3-activated $T$ cells. These results confirm the presence of $B$ cell precursors for autoantibodies in the preimmune as well as normal adult repertoire, and indicate that the production of antiDNA and RF appears to be regulated independently. (J. Clin. Invest. 1990. 85:899-903.) rheumatoid factor • anti-DNA • B cell repertoire $\bullet$ anti-CD3, B cell stimulation $\bullet$ neonatal immune response
\end{abstract}

\section{Introduction}

The hallmark of autoimmune diseases is the expression of antibodies to normal host constituents. These antibodies serve as markers of diagnostic and prognostic significance and in some instances have been directly implicated in the inflammation and organ damage characteristic of these diseases (1). Despite the close association of autoantibodies with pathogenetic events, precursors for these antibodies appear to be present in the B cell repertoire of normal humans as well as animals. Indeed, precursors for two autoantibodies, anti-DNA and rheumatoid factor (RF), ${ }^{1}$ occur with high frequency in the $B$ cell repertoire of normal mice with their numbers exceeding those for some foreign antigens (2-6). The function of these autoantibodies is unknown, although they are presumed to provide a beneficial set of specificities either for immunoregulation or cross-reaction with foreign antigens.

Address reprint requests to Dr. S. Pisetsky, Veterans Administration Hospital, Box 151G, 508 Fulton Street, Durham, NC 27705.

Received for publication 21 July 1989 and in revised form $2 \mathrm{No}-$ vember 1989.

1. Abbreviations used in this paper: RF, rheumatoid factor; SA, Staphylococcus aureus.

The Journal of Clinical Investigation, Inc.

Volume 85, March 1990, 899-903
Unlike studies with the mouse, which have involved direct enumeration of precursors among stimulated lymphocytes, characterization of the human B cell repertoire for autoantibodies has in general been less direct and based primarily on analysis of monoclonal antibodies, either paraproteins, or products of hybridomas or EBV transformation (7-12). Among these antibodies, anti-DNA and RF, as well as broadly reactive autoantibodies termed natural autoantibodies, occur commonly; natural autoantibodies bind DNA as well as other self antigens $(6,9)$. On the assumption that monoclonal antibodies or EBV transformants are representative of normal B cell populations, it has been postulated that a high frequency of autoantibody producers resides in the normal human B cell repertoire. Direct analysis of the frequency of human B cell precursors stimulated to produce autoantibodies by polyclonal activators has been reported in less detail $(13,14)$.

Recent studies from one of our laboratories have described a system for the in vitro stimulation of B cells at high efficiency $(15,16)$. Culture of peripheral blood B lymphocytes with irradiated or mitomycin C-treated $\mathrm{T}$ cells stimulated by monoclonal antibodies to CD3 adhered to plastic can lead to antibody production by $>50 \%$ of $\mathrm{B}$ cells. This system is dependent on contact between $B$ and $T$ cells and presumably involves factors produced by stimulated $T$ cells. Since the precursor frequency of $\mathrm{B}$ cells induced to secrete immunoglobulin is much greater with this mode of stimulation compared with other polyclonal B cell activators, it was employed to estimate the capacity of various B cell populations to produce autoantibodies.

In the studies reported herein, we have investigated IgM responses, including anti-DNA and RF, by peripheral blood as well as cord blood $\mathrm{B}$ lymphocytes under various conditions of in vitro culture, including anti-CD3 stimulation. Cord blood lymphocytes were evaluated to assess the preimmune repertoire in terms of its requirements for in vitro stimulation, as well as representation of autoantibody precursors. In these experiments, adult $T$ cell populations were used to support $B$ cell expression because of the deficiency in helper $\mathrm{T}$ cell function of cord blood lymphocytes (17). Our data indicate that B cells from normal adults as well as cord blood lymphocytes have appreciable RF and anti-DNA production when induced by anti-CD3, with RF production demonstrable as well with stimulation by Staphylococcus aureus (SA) Cowan I and T cell cytokines. These data support the notion that some autoantibody specificities are ordinarily present in the normal as well as preimmune human B cell repertoire.

\section{Methods}

Reagents. Formalinized Cowan-I strain SA was purchased from Calbiochem-Behring Corp., San Diego, CA, and was used at a concentration of 1/60,000 vol/vol. PHA was purchased from Burroughs-Wellcome, Research Triangle Park, NC. 4 $\beta$-Phorbol 12-myristate 13-acetate (PMA) was purchased from Sigma Chemical Co., St. Louis, MO and was dissolved in ethanol for use in culture. 
Cell preparation. PBMC were obtained from healthy adult volunteers or from umbilical cord blood by centrifugation of heparinized venous blood over sodium diatrizoate/ficoll gradients (Isolymph; Gallard-Schlesinger Chemical Mfg. Corp., Carle Place, NY). Cells were washed three times in Hanks' balanced salt solution before additional processing.

Cell purification. PBMC were separated into T cell- and B cellenriched populations as described (15). Briefly, PBMC were depleted of monocytes and NK cells by incubation with $5 \mathrm{mM}$ L-leucine methyl ester $\mathrm{HCl}$ (Sigma Chemical Co.) in serum-free RPMI-1640 (Inland Laboratories, Austin, TX). The treated cell population was washed twice with medium RPMI supplemented with penicillin $G(200 \mathrm{U} / \mathrm{ml})$, gentamicin $(10 \mu \mathrm{g} / \mathrm{ml}), \mathrm{L}$-glutamine $(0.3 \mathrm{mg} / \mathrm{ml})$, and $10 \% \mathrm{FBS}$ (Gibco Laboratories, Grand Island, NY), and then was incubated with neuraminidase-treated sheep red blood cells (SRBC). The rosetting and nonrosetting populations were then separated by centrifugation on diatrizoate/ficoll gradients. The nonrosetting cells were obtained from the interface and were again rosetted and centrifuged on diatrizoate/ ficoll gradients to remove residual $\mathrm{T}$ cells. The resultant population of B cells contained $<2 \%$ esterase-positive monocytes and $<1 \% \mathrm{~T}$ cells as determined by staining with OKT3 and OKT11 (American Type Culture Collection, Rockville, MD) pan T cell mAb, followed by analysis with a fluorescence-activated cell sorter. The cells were additionally characterized as containing $>90 \% \mathrm{CD} 20$-positive $\mathrm{B}$ cells and no CD16- (Leu-11b; Becton Dickinson Immunocytometry Systems, Mountain View, CA) positive NK cells. The sedimented rosette-forming cells from the first centrifugation were treated with isotonic $\mathrm{NH}_{4} \mathrm{Cl}$ to lyse the SRBC and then were passed over a nylon wool column. Cells prepared in this manner contained $>95 \% \mathrm{CD} 3+\mathrm{T}$ cells. $\mathrm{T}$ cells were treated with mitomycin $\mathrm{C}$ before culture. This was accomplished by suspending $T$ cells in culture medium at $\sim 5 \times 10^{6} / \mathrm{ml}$ and incubating them on a rotator for $45 \mathrm{~min}$ at $37^{\circ} \mathrm{C}$ with mitomycin $\mathrm{C}$ at a concentration of $40 \mu \mathrm{g} / \mathrm{ml}$. Afterward, the cells were washed four times and suspended in culture medium for use.

Generation of mitogen-stimulated $T$ cell supernatants $(T F)$. T cells were suspended in medium with $10 \%$ FBS at a concentration of $5 \times 10^{6}$ cells $/ \mathrm{ml}$ and incubated with $1 \mu \mathrm{g} / \mathrm{ml}$ of PHA and $1 \mathrm{ng} / \mathrm{ml}$ of PMA for 2 $h$ at $37^{\circ} \mathrm{C}$. The cells were then washed and resuspended in fresh culture medium at $5 \times 10^{6} / \mathrm{ml}, 2 \mathrm{ml} / 17 \times 100-\mathrm{mm}$ round-bottomed tube. After $48 \mathrm{~h}$, the supernatants were harvested, filtered, and kept at $-20^{\circ} \mathrm{C}$ until used.

Technique of cell culture for generation of immunoglobulin-secreting cells. Microtiter wells were coated with anti-CD3 mAb as previously described (15). Briefly, the anti-CD3 $\mathrm{mAb}, 64.1$, was diluted in RPMI-1640 at a concentration of $4 \mu \mathrm{g} / \mathrm{ml} .50 \mu \mathrm{l}$ were placed in each of the wells of 96-well microtiter plates with flat-bottomed wells (No. 3596; Costar Data Packaging Corp., Cambridge, MA) and incubated at room temperature for $1 \mathrm{~h}$. The wells were then washed twice in medium to remove nonadherent MAb before addition of cells. Approximately $14-20 \%$ of the added MAb adhered to the wells. Routine cultures were carried out in triplicate in a total volume of $200 \mu \mathrm{l}$. Adult or neonatal B cells $\left(2.5 \times 10^{4} /\right.$ well $)$ were cultured with $1 \times 10^{5}$ mitomycin C-treated adult T cells. SA or supernatants of mitogen-activated adult $\mathrm{T}$ cells were added where indicated. The cells were incubated routinely for $10-14 \mathrm{~d}$ at $37^{\circ} \mathrm{C}$ in a humidified atmosphere of $5 \% \mathrm{CO}_{2}$ and $95 \%$ air, after which supernatants were harvested and analyzed for immunoglobulin and autoantibody content.

Immunoassays. Total IgM, RF anti-DNA, and RF levels were assessed by ELISA by modifications of published methods (3). For total IgM, wells of 96-well polystyrene plates (Dynatech Laboratories, Chantilly, VA) were coated with $2.5 \mu \mathrm{g} / \mathrm{ml}$ of $F\left(a^{\prime}\right)_{2}$ fragments of a goat anti-human $F\left(a b^{\prime}\right)_{2}$ specific reagent (Organon Teknika-Cappel Laboratories, Malvern, PA) in $8 \mathrm{M}$ urea 0.01 Tris pH 7.0; coating antigen for the $R F$ assay was $2.5 \mu \mathrm{g} / \mathrm{ml}$ of rabbit IgG (Sigma Chemical Co.) in $8 \mathrm{M}$ urea $0.01 \mathrm{M}$ Tris $\mathrm{pH} 7.0$ whereas the coating antigen for the anti-DNA assay was single-stranded DNA (Sigma Chemical Co., boiled $10 \mathrm{~min}$ and rapidly cooled in ice bath) at $5 \mu \mathrm{g} / \mathrm{ml}$ in standard saline citrate (SSC) buffer ( $\mathrm{pH} \mathrm{8.0)}$ ). After overnight incubation of these antigens at $4^{\circ} \mathrm{C}$, wells were post-coated for $1 \%$ bovine serum $1 \mathrm{~h}$ at room temperature and then washed three times with PBS containing $0.05 \%$ Tween 20 (PBS-Tween). After washing, wells were incubated with dilutions of tissue culture supernatants or control antibodies in PBS-Tween containing 1\% BSA. After additional washing, wells were incubated with a 1:400 dilution of a peroxidase conjugate goat antihuman IgM reagent (mu chain-specific; Sigma Chemical Co.) followed by $3,3^{\prime}, 5,5^{\prime}$ tetramethylbenzidine in $0.1 \mathrm{M}$ citrate buffer containing 1:3000 $\mathrm{H}_{2} \mathrm{O}_{2}$. Optical densities at $380 \mathrm{~nm}$ were then measured using a Titertek Multiskan platereader (Flow Laboratories, Inc., McLean, VA).

In these experiments, IgM values were calculated on the basis of a standard curve using purified human IgM (Organon Teknika-Cappel). ELISA values for RF and anti-DNA assays are reported directly, although all assays contained controls to assure comparability of assay performance. The control for RF determinations was the monoclonal RF GLO (gift of Dr. Dennis Carson, Scripps Clinic and Research Foundation, La Jolla, CA) whereas a monoclonal IgM anti-DNA paraprotein (gift of Dr. Wayne Rundles, Duke University Medical Center, Durham, NC) or an affinity-purified 3I anti-DNA preparation (gift of Dr. Betty Diamond, Albert Einstein College of Medicine, Bronx, NY) were used for anti-DNA assays.

Antibodies to other nucleic acid antigen were also measured by ELISA. For these determinations, poly I and poly dT (products of Pharmacia Fine Chemicals, Piscataway, NJ) were coated to microtiter plates at $5 \mu \mathrm{g} / \mathrm{ml}$ in PBS overnight at $4^{\circ} \mathrm{C}$ while double-stranded DNA (native calf thymus DNA treated with $\mathrm{S} 1$ nuclease) was coated at 5 $\mu \mathrm{g} / \mathrm{ml}$ in SSC under similar conditions. Assays with these antigens were performed as previously described.

\section{Results}

To determine the capacity and specificity of the ELISA assays for detecting RF and anti-DNA, the activity of control antibodies was assessed. The control for RF was the monoclonal RF GLO while the anti-DNA control was an affinity purified anti-DNA antibody preparation obtained using as antiidiotype column. As shown in Fig. 1, both anti-DNA and RF levels could be measured over a wide range of protein concentrations, although with these control antibodies, RF activity could be detected at a lower protein concentration than antiDNA. Both assays were, however, sensitive to at least 0.5 $\mu \mathrm{g} / \mathrm{ml}$ of specific antibody. Since individual anti-DNA and RF show a considerable range of binding activities for their respective antigens, the relative sensitivities of these assays cannot be assessed. For convenience, OD values for the ELISA are therefore reported directly. Total IgM values are reported as micrograms per milliliter protein assessed from ELISA using pooled purified IgM as standard.

Table I presents results of a representative experiment assessing the total IgM response of PBL from adults as well as

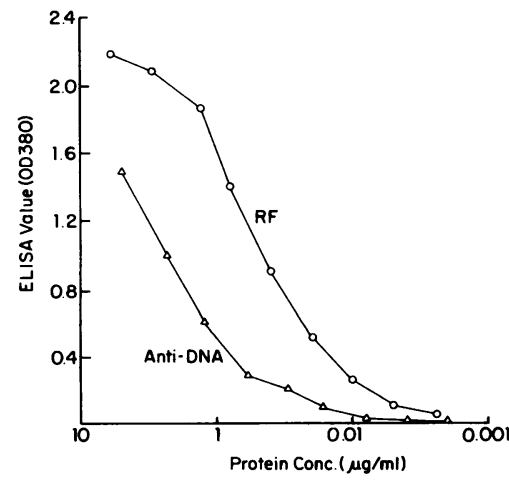

Figure 1. Sensitivity of RF and anti-DNA assays. The sensitivity of autoantibody ELISAs was assessed using as standards the monoclonal RF GLO antibody and an affinity-purified 3I idiotype-positive anti-DNA preparation. Results are reported in terms of OD380 values. 
Table I. In Vitro IgM Antibody Production by Cord Blood and Adult $B$ Cells

\begin{tabular}{lccc}
\hline & & \multicolumn{2}{c}{ Total IgM } \\
\cline { 3 - 4 } \multicolumn{1}{c}{ Stimulus } & $\begin{array}{c}\text { T cell } \\
\text { factors }\end{array}$ & Adult (3) & Cord (7) \\
\hline & & \multicolumn{2}{c}{$\mu g / m l$} \\
SA & 0 & $0.193 \pm 0.284$ & $0.177 \pm 0.114$ \\
Nil & + & $0.557 \pm 0.273$ & $0.127 \pm 0.122$ \\
SA & + & $5.028 \pm 0.269$ & $8.129 \pm 0.170$ \\
Adult T cells & 0 & $0.092 \pm 0.083$ & $0.068 \pm 0.067$ \\
Adult T cells & + & $2.329 \pm 0.153$ & $0.250 \pm 0.130$ \\
Anti-CD3 + adult T & 0 & ND & ND \\
Anti-CD3 + adult T & + & $4.106 \pm 0.119$ & $8.763 \pm 0.753$ \\
& & & \multicolumn{3}{c}{}
\end{tabular}

cord blood B lymphocytes. These data indicate that IgM production can be elicited from the cord B lymphocytes under a variety of conditions, with some differences noted compared with adult B cells. Thus, high levels of IgM production by cord blood B cells were obtained with stimulation by either anti$\mathrm{CD} 3$ in the presence of $\mathrm{T}$ cell factors or $\mathrm{SA}$ with $\mathrm{T}$ cell factors. These conditions also produced significant stimulation for adult B cells, although adult cells also showed appreciable IgM production with $\mathrm{T}$ cell factors alone, as well as $\mathrm{T}$ cell factors in the presence of adult $T$ cells.

To evaluate conditions for autoantibody production by cord B cells and the magnitude of these responses, anti-DNA and RF production were next measured by ELISA and compared with total IgM responses. As shown in Table II, RF production was observed in general under the same conditions of stimulation as that inducing total IgM, with the highest responses found in the presence of $\mathrm{SA}+\mathrm{T}$ cell factors as well as anti-CD3-stimulated $\mathrm{T}$ cells $+\mathrm{T}$ cell factors. Anti-DNA production showed a different response pattern, with antibody levels from cultures stimulated by anti-CD3-activated $T$ cells and $T$ cell factors much greater than those from cultures stimulated by $S A$ and $T$ cell factors. Similar results were noted when responses of adult B cells were examined (Table III), although some differences were found among individuals in the magnitude of their anti-DNA responses under various stimulating conditions. These differences may reflect the prior state of B cell activation.

The binding of cord blood IgM to DNA was characterized further to confirm specificity for DNA determinants. By competition ELISA, ssDNA effectively inhibited antibody binding to the solid phase DNA antigen. ssDNA at a concentration of 5 $\mu \mathrm{g}$ inhibited DNA binding by $69 \%$ (average of two determinations) and at a concentration of $0.5 \mu \mathrm{g} / \mathrm{ml}$ by $59 \%$ (average of two determinations). These results indicate that the induced antibodies were not simply nonspecifically reactive to solid phase antigen. Furthermore, IgM antibodies found in these cultures bound synthetic polynucleotides as well as ssDNA, indicating that the binding was directed to nucleic acid determinants rather than any non-nucleic acid component in the ssDNA preparation (Fig. 2). These results do not exclude, however, the presence of coincidentally produced antibodies to nuclear proteins. In addition to antibodies to ssDNA, small amounts of antibodies to double-stranded DNA could also be demonstrated in some cultures.

Because of reports that human B cells can produce polyreactive antibodies with both anti-DNA and RF activity (18), the relationship between these antibodies in the cord blood supernatants was tested by inhibition ELISA. Thus, DNA at a concentration of $5 \mu \mathrm{g} / \mathrm{ml}$ did not affect RF binding while producing $>50 \%$ inhibition of DNA binding; DNA at an inhibitor concentration 10 -fold higher $(50 \mu \mathrm{g} / \mathrm{ml})$ similarly was without effect on RF binding. These results indicate that the predominant RF were not cross-reactive anti-DNA antibodies, but rather a distinct population.

\section{Discussion}

The studies presented herein demonstrate that B cells from normal adults as well as cord blood can be readily induced in vitro to produce two autoantibodies, $R F$ and anti-DNA. These findings confirm observations in the mouse on in vitro induction of autoantibodies by normal cells stimulated by polyclonal activators, as well as studies in humans using EBV transformation to elicit antibody production. Together, these studies document the frequent representation of autoantibody B cell precursors among normals, supporting further the notion that these specificities occupy an essential role in the preimmune as well as adult repertoire.

Table II. In Vitro Autoantibody Production by Cord Blood B Cells*

\begin{tabular}{|c|c|c|c|c|}
\hline \multirow[b]{2}{*}{ Stimulus } & \multirow[b]{2}{*}{$T$ cell factors } & \multicolumn{2}{|c|}{ Antibody production } & \multirow[b]{2}{*}{ Anti-DNA } \\
\hline & & Total IgM & $\mathbf{R F}$ & \\
\hline & & $\mu g / m l$ & \multicolumn{2}{|c|}{$O D$ units } \\
\hline SA & 0 & $0.125 \pm 0.060$ & $0.066 \pm 0.037$ & $0.011 \pm 0.011$ \\
\hline Nil & + & $0.234 \pm 0.500$ & $0.015 \pm 0.019$ & $0.005 \pm 0.005$ \\
\hline SA & + & $6.340 \pm 0.004$ & $0.952 \pm 0.535$ & $0.075 \pm 0.030$ \\
\hline Adult T cells & 0 & $0.010 \pm 0.010$ & $0.003 \pm 0.001$ & $0.001 \pm 0.001$ \\
\hline Adult $\mathrm{T}$ cells & + & $0.316 \pm 0.549$ & $0.011 \pm 0.007$ & $0.005 \pm 0.007$ \\
\hline Anti-CD3 + adult $T$ cells & 0 & $4.819 \pm 0.302$ & $0.364 \pm 0.293$ & $0.237 \pm 0.240$ \\
\hline Anti-CD3 + adult $T$ cells & + & $16.890 \pm 0.060$ & $0.717 \pm 0.304$ & $0.506 \pm 0.250$ \\
\hline
\end{tabular}

* Results are shown for mean \pm SD of four cord blood B cell samples. 
Table III. In Vitro Autoantibody Production by Adult B Cells

\begin{tabular}{|c|c|c|c|c|c|}
\hline \multirow[b]{2}{*}{ Stimulus } & \multirow{2}{*}{$\begin{array}{l}\mathrm{T} \text { cell } \\
\text { factors }\end{array}$} & \multicolumn{2}{|c|}{ Exp. $1^{*}$} & \multicolumn{2}{|c|}{ Exp. 2} \\
\hline & & $\mathbf{R F}^{*}$ & Anti-DNA & $\mathbf{R F}$ & Anti-DNA \\
\hline SA & 0 & 0.024 & 0.000 & ND & 0.000 \\
\hline Nil & + & 0.019 & 0.000 & ND & 0.024 \\
\hline SA & + & 0.317 & 0.050 & ND & 0.052 \\
\hline Adult $\mathrm{T}$ & 0 & 0.007 & 0.000 & ND & 0.025 \\
\hline Adult $\mathrm{T}$ & + & 0.073 & 0.010 & ND & 0.694 \\
\hline Anti-CD3 $+T$ cells & 0 & 1.223 & 0.602 & 1.066 & 0.154 \\
\hline Anti-CD3 + T cells & + & 1.150 & 0.651 & 1.775 & 0.560 \\
\hline
\end{tabular}

* Each experiment represents results of a single adult donor.

${ }^{\ddagger}$ Results are reported as OD380 units.

The system we have used allows direct evaluation of B cell populations under conditions of intense, non-antigen-specific activation. These cultures provide appreciable antibody production over a period of 7-12 d and are simpler to perform than EBV transformation. In this regard, stimulation of B cells by $T$ cells activated with antibodies to CD3 in the presence of $T$ cell-derived factors appears to produce a more generalized stimulation of $B$ cells than SA plus $T$ cell factors. Thus, whereas SA plus $T$ cell factors caused stimulation of RF without appreciable anti-DNA production, anti-CD3-activated $T$ cells with $T$ cell factors induced both RF and anti-DNA. This pattern was observed in adult as well as cord blood B cells. These results are consistent with previous observations on the preferential induction of RF by SA stimulation (14) and also indicate that $B$ cell stimulation by intact activated $T$ cells is required for induction of anti-DNA antibodies. These results suggest that precursors of RF and anti-DNA-secreting cells may reside within individual subpopulations of $B$ cells with different activation requirements.

The phenotypic and functional properties of cord blood lymphocytes have been extensively evaluated to study the ontogeny of human immune responses. These studies have demonstrated both quantitative and qualitative differences of $B$ and $T$ cell populations that could influence antibody production. Thus, cord blood B cells display intact IgM responses but low IgG and IgA responses in vitro despite levels of surface isotype expression similar to adults $(17,19)$. These responses can be elicited by stimulation with EBV but not pokeweed mitogen because of functional disturbances of cord blood $T$ lymphocytes. $T$ cells from cord blood indeed are characterized by deficient helper cell function, suppression of in vitro $B$ cell responses, as well as dysregulation of cytokine production (17,

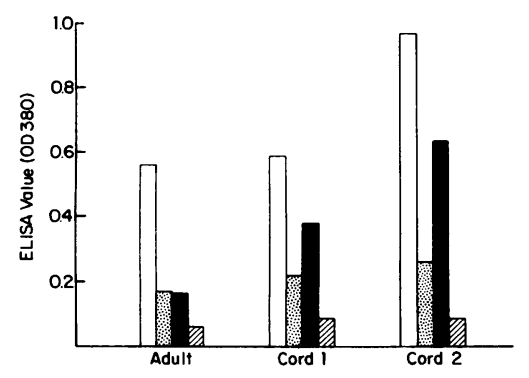

Figure 2. In vitro antibody production to nucleic acid antigens. IgM antibodies in tissue culture supernatants were assayed by ELISA for binding to ssDNA (open bar); poly I (stippled bar); poly dT (filled bar) and dsDNA (hatched bar). Results are reported in terms of OD380 values.
19, 20-24). The ratio of CD4+ and CD8+ cord blood T cells is also different from adults, but not correlated with the ability to provide help for B cell responses (25). The origin of these functional differences has not yet been elucidated, although they have been postulated to be important in regulating the fetal-maternal state. Because of the inability of cord blood cells to provide $\mathrm{T}$ cell help for in vitro antibody production, only adult $T$ cells have been used in our experiments to stimulate cord blood B cells. The use of adult $T$ cell populations allows assessment of the response of these cells, as reported in other systems for in vitro stimulation (17).

Precise quantitation of the magnitude of the induced antiDNA response in these cultures is difficult because of the heterogeneity in the immunochemical properties of anti-DNA antibodies. Thus, among panels of monoclonal anti-DNA from both mouse and man, there is a marked variability in the specific activity of DNA binding $(26,27)$. This value, which has been defined as the concentration of protein producing a given level of DNA binding, likely reflects the avidity of antiDNA antibodies for DNA antigen as well as the density along the DNA molecule of unique antigenic sites. At present, we do not have data on the specific activity of the anti-DNA induced in these culture systems and therefore cannot measure the total amount of antibody comprising the anti-DNA response; calculation of these values using a monoclonal antibody as an arbitrary control provides at best an approximation of the magnitude of this response. Similarly, it is not yet known whether there are differences in the number of anti-DNA precursors among adults and cord blood B lymphocytes, or the array of anti-DNA specificities represented in these repertoires. In this regard, studies on monoclonal anti-DNA antibodies derived by EBV transformation of lymphocytes from normals, as well as patients with systemic lupus erythematosus, have indicated that lupus patients have a higher frequency of anti-DNA precursors and that these antibodies have higher affinity for DNA (12). These observations have suggested a role for antigen selection in determining the B cell repertoire during disease. A similar study concerning the nature of such specificities in the preimmune repertoire and their evolution during ontogeny would be informative about the role of normal antigen exposure.

Although the presence of autoantibody precursors in the normal B cell repertoire is now well established, the function of these antibodies and their pathogenic potential remains unclear. One clue to their function is the demonstration that many of these antibodies are polyspecific (or polyreactive) and bind more than one antigen, both self and foreign $(28,29)$. Indeed, antibodies with both IgG and DNA binding have been identified among such polyreactive, natural autoantibodies. Many of these autoantibodies are likely to be of only low avidity, although they may play a possible physiological role as the initial defense to foreign antigenic challenge. Because of their wide pattern of reactivity, a limited set of polyreactive antibodies could therefore provide a prompt, albeit low-avidity response to many different foreign antigens, pending the development of more specific, higher avidity antibodies. The expression of these antibodies would not be expected to be pathogenic because their binding to self antigen, like foreign antigen, would have low avidity and their expression would only be transient.

The spectrum of polyreactive binding of the induced antibodies in our cultures has not been determined. It appears likely, however, that polyreactive antibodies with both anti- 
DNA and RF activity are not prominent components of the induced response and that RF and anti-DNA antibodies are largely nonoverlapping populations, only some of whose members have cross-reactive IgG and DNA binding (18). Thus, the IgG-binding RF induced in our cultures were not inhibited by soluble DNA even under conditions causing marked inhibition of anti-DNA. These results indicate that the RF antibodies in highest concentration lacked significant DNA binding activity. Fürthermore, RF and anti-DNA production was stimulated under different conditions, since SA and $T$ cell factors induced high levels of RF production without a comparable anti-DNA response, whereas anti-CD3stimulated $T$ cells induced both. Cross-reactive antibodies with both anti-DNA and RF activity may have been induced in these cultures, although they would appear to be a less abundant fraction of the antibodies.

Because of the efficiency of antibody induction in this system, it should be possible to assess the B cell repertoire for different autoantibody specificities directly in normals as well as various disease populations. Current studies are directed to assessing the anti-DNA response of patients with systemic lupus erythematosus, seeking to identify both quantitative as well as qualitative alterations in composition of the autoantibody repertoire.

\section{Acknowledgments}

This work was supported by National Institutes of Health grants 5P01-AI-23308 and 5P50-AR-39162, and the Veterans Administration Medical Research Service.

\section{References}

1. Tan, E. M. 1982. Autoantibodies to nuclear antigens: their immunobiology and medicine. Adv. Immunol. 33:167-240.

2. Dziarski, R. 1982. Preferential induction of autoantibody secretion in polyclonal activation by peptidoglycan and lipopolysaccharide. J. Immunol. 128:1018-1025.

3. Pisetsky, D. S., and S. A. Caster. 1982. The B cell repertoire for autoantibodies: frequency of precursor cells for anti-DNA antibodies. Cell. Immunol. 72:294-305.

4. Conger, J. D., B. L. Pike, and G. J. V. Nossal. 1987. Clonal analysis of the anti-DNA repertoire of murine B lymphocytes. Proc. Natl. Acad. Sci. USA. 84:2931-2935.

5. Klinman, D. M., and A. D. Steinberg. 1987. Systemic autoimmune disease arises from polyclonal B cell activation. J. Exp. Med. 165:1755-1760.

6. Dighiero, G., P. Lymberi, D. Holmberg, I. Lundquist, A. Coutinho, and S. Avrameas. 1985. High frequency of natural autoantibodies in normal newborn mice. J. Immunol. 134:765-771.

7. Fong, S., C. D. Tsoukas, L. A. Frincke, S. K. Lawrence, T. L. Holbrook, J. H. Vaughan, and D. A. Carson. 1981. Age-associated changes in Ebstein-Barr virus-induced human lymphocyte autoantibody responses. J. Immunol. 126:910-914.

8. Welch, M. J., S. Fong, J. Vaughan, and D. Carson. 1983. Increased frequency of rheumatoid factor precursor B lymphocytes after immunization of normal adults with tetanus toxoid. Clin. Exp. Immunol. 51:299-304.

9. Dighiero, G., B. Guilbert, J.-P. Fermand, P. Lymberi, F. Danon, and S. Avrameas. 1983. Thirty-six human monoclonal immunoglobulins with antibody activity against cytoskeleton proteins, thyroglobulin and native DNA: immunologic studies and clinical correlations. Blood. 62:264-270.
10. Hoch, S., P. H. Schur, and J. Schwaber. 1983. Frequency of anti-DNA producing cells from normals and patients with systemic lupus erythematosus. Clin. Immunol. Immunopathol. 27:28-37.

11. Cairns, E., J. Block, and D. A. Bell. 1984. Anti-DNA producing hybridomas of normal human lymphoid cell origin. J. Clin. Invest. 74:880-887.

12. Nakamura, M., S. E. Burastero, Y. Ueki, J. W. Larrick, A. L. Notkins, and P. Casali. 1988. Probing the normal and autoimmune B cell repertoire with Epstein-Barr virus. Frequency of B cells producing monoreactive high affinity autoantibodies in patients with Hashimoto's disease and systemic lupus erythematosus. J. Immunol. 141:4165-4172.

13. Levy, R. J., M. Haidar, H. Park, L. Tar, and A. I. Levinson. 1986. Bacterial peptidoglycan induced in vitro rheumatoid factor production by lymphocytes of healthy subjects. Clin. Exp. Immunol. 64:311-317.

14. Levison, A. I., N. F. Dalal, M. Haidar, L. Tar, and M. Orlow. 1987. Prominent IgM rheumatoid factor production by human cord blood lymphocytes stimulated in vitro with Staphylococcus aureus cowan I. J. Immunol. 139:2237-2241.

15. Hirohata, S., D. F. Jelinek, and P. E. Lipsky. 1988. T cell-dependent activation of $B$ cell proliferation and differentiation by immobilized monoclonal antibodies to CD3. J. Immunol. 140:37263744.

16. Geppert, T. D., and P. E. Lipsky. 1988. Activation of T lymphocytes by immobilized antibodies to CD3. Regulatory influences of monoclonal antibodies to additional $\mathrm{T}$ cell surface determinants. $J$. Clin. Invest. 81:1497-1505.

17. Andersson, U., A. G. Bird, S. Britton, and R. Palacios. 1981. Humoral and cellular immunity in humans at the cell level from birth to two years of age. Immunol. Rev. 57:5-38.

18. Rauch, J., H. Tannenbaum, K. Straaton, H. Massicotte, and J. Wild. 1986. Human-human hybridoma autoantibodies with both anti-DNA and rheumatoid factor activities. J. Clin. Invest. 77:106112.

19. Hayward, A. R. 1981. Development of lymphocyte responses and interactions in the human fetus and newborn. Immunol. Rev. 57:39-60.

20. Hayward, A. R., and A. R. Lawton. 1977. Induction of plasma cell differentiation of human fetal lymphocytes: evidence for functional immaturity of T and B cells. J. Immunol. 119:1213-1217.

21. Durandy, A., A. Fischer, and C. Griscelli. 1979. Active suppression of B lymphocyte maturation by two different newborn $T$ lymphocyte subsets. J. Immunol. 123:2644-2650.

22. Tosato, G., I. T. Magrath, I. R. Koski, N. T. Dooley, and R. M. Blaese. 1980. B cell differentiation and immunoregulatory $T$ cell function in human cord blood lymphocytes. J. Clin. Invest. 66:383-388.

23. Andersson, U., S. Britton, M. Deley, and G. Bird. 1983. Evidence for the ontogenic precedence of suppressor $T$ cell functions in the human neonate. Eur. J. Immunol. 13:6-13.

24. Yachie, A., T. Miyawaki, T. Nagaoki, T. Yokoi, M. Mukai, N. Uwanda, and N. Taniguchi. 1981. Regulation of B cell differentiation by $T$ cell subsets defined with monoclonal OKT4 and OKT8 antibodies in human cord blood. J. Immunol. 127:1314-1317.

25 . Wäkàsugi, N., and J.-L. Virelizier. 1985. Defective IFN- $\gamma$ production in the human neonate. I. Dysregulation rather than intrinsic abnormality. J. Immunol. 34:167-171.

26. Marion; T. N., A. R. Lawton, J. F. Kearney, and D. E. Briles. 1982. Anti-DNA autoantibodies in (NZB $\times$ NZW) F1 mice are clonally heterogeneous but the majority share a common idiotype. J. Immunol. 128:668-674.

27. Smeenk, R. J. T., K. Brinkman, H. G. van den Brink, and A. A. A. Westgeest. 1988. Reaction patterns of monoclonal antibodies to DNA. J. Immunol. 140:3786-3792.

28. Schwartz, R. S., and B. D. Stollar. 1985. Origins of anti-DNA autoantibodies. J. Clin. Invest. 75:321-327.

29. Emlen, W., D. S. Pisetsky, and R. P. Taylor. 1986. Antibodies to DNA: a perspective. Arthritis Rheum. 29:1417-1426. 